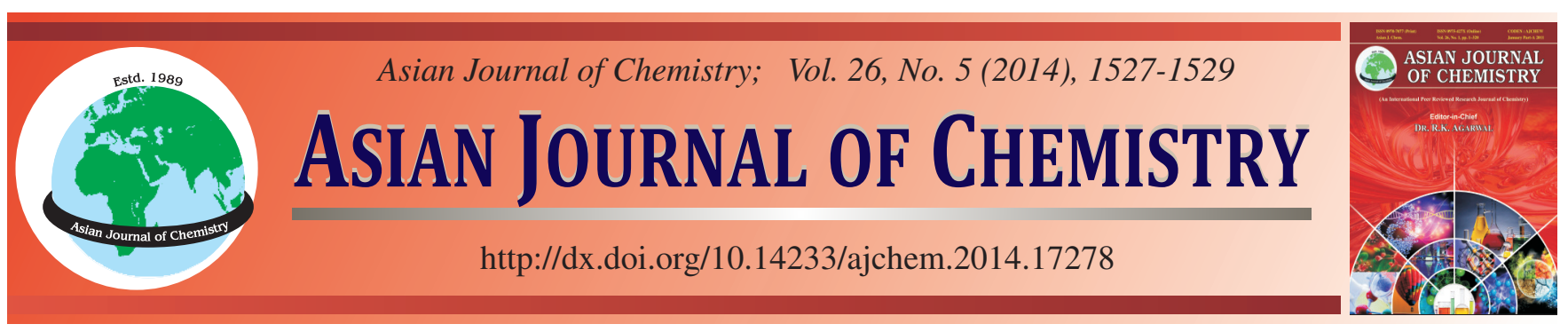

\title{
Thermal Stability and Thermal Degradation Reaction Kinetics of 4,4'-Diphenylmethane Diisocyanatetrimer $\dagger$
}

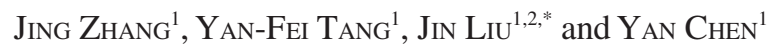

\author{
${ }^{1}$ School of Materials and Chemical Engineering, Anhui Jianzhu University, Hefei 230022, P.R. China \\ ${ }^{2}$ Anhui Key Laboratory of Advanced Building Materials, Anhui Jianzhu University, Hefei 230022, P.R. China
}

*Corresponding author: E-mail: liujin@ahjzu.edu.cn

\begin{abstract}
The trimer of 4,4'-diphenylmethane diisocyanate (MDI) is synthesized using 2,4,6-tris(dimethylaminomethyl) phenol (DMP-30) as catalyst. The thermal stability of MDI and its trimer and thermal degradation reaction kinetics for MDI trimer are studied by thermo gravimetric analyzer, respectively. The properties and structure of the trimer of MDI are characterized by X-ray diffraction, Fourier transform infrared spectroscopy and TGA. The activation energy of degradation reaction of the trimer was obtained by Ozawa method. The results show that there are two stages of the trimer during thermal degradation process and the apparent activation energy of the first and the second stage are 200.99 and $259.94 \mathrm{~kJ} / \mathrm{mol}$, respectively.
\end{abstract}

Keywords: Trimer of 4,4'-diphenylmethane diisocyanate, Thermal stability, Reaction kinetics, Ozawa method.

\section{INTRODUCTION}

Aromatic or aliphatic isocyanate can be self-addition reaction to get isocyanurate. There is no active hydrogen atom in isocyanurate ring and the unit structure become more stabile. The products containing isocyanurate ring possess high protective properties, good corrosion resistance and yellowing resistance, good heat resistance and flame retardant. Because of these properties, the isocyanate trimer had been widely used in many fields such as coatings, adhesives, sealant elastomers, foamed plastic, etc.

Now the published literature were reported more about toluene diisocyanate (TDI) trimer, 1,6-hexamethylenediisocyanatetrimer (HDI), isophoronediisocyanate (IPDI) trimer, but little about diphenylmethanediisocyanate (MDI) trimer ${ }^{1-8}$. In this study, MDI trimer is synthesized by using solution polymerization. The thermal stability of the trimer is compared with MDI monomer and their thermal degradation reaction kinetics has been explored.

\section{EXPERIMENTAL}

Characterization: The structure of the products was ascertained by XRD (D8 Advance, BRUKER, Germany) at $40 \mathrm{kV}$ and $40 \mathrm{~mA}$ with a $\mathrm{CuK}_{\alpha}$ radiation source. The spectra were recorded by using a WQF-300 spectrometer (Beijing, China) with 32 scans and $4 \mathrm{~cm}^{-1}$ resolution at the range $4000-400 \mathrm{~cm}^{-1}$. The DTG and TGA were measured used STA409PC (NETZSCHGerätebau $\mathrm{GmbH}$, Germany) thermal analyzer with the heating rate at $10,15,20,30 \mathrm{~K} / \mathrm{min}$, respectively and high pure $\mathrm{N}_{2}$ as shelter gas. The range of temperature was controlled from 50$800{ }^{\circ} \mathrm{C}$.

Preparation of the trimer of MDI: $100 \mathrm{~mL}$ of dehydrated toluene and $50 \mathrm{~g}$ of MDI are mixed under the protection of high purity $\mathrm{N}_{2}$, MDI has absolutely dissolved in toluene by heating with stirring and adding proper amount of $0.05 \%$ of DMP-30 as catalyst. Stirring is continued at $60^{\circ} \mathrm{C}$ for $6 \mathrm{~h}$. The excess MDI monomer and catalyst were removed by washing with toluene.

\section{RESULTS AND DISCUSSION}

Infrared spectroscopic analysis: There is only-NCO absorption peak at $2274 \mathrm{~cm}^{-1}$ in MDI infared spectroscopy as shown in Fig. 1 and the absorption peak intensity of MDI after polymerization at $2274 \mathrm{~cm}^{-1}$ is weaker than MDI monomer. The absorption peak of isocyanurate ring are obviously found at 1720 and $1410 \mathrm{~cm}^{-1}$, but the absorption peak of carbodiimide structureis not be found ${ }^{9}$. In general, the formation of carbodiimide structure cannot be happened unless at high temperature,

†Presented at The 7th International Conference on Multi-functional Materials and Applications, held on 22-24 November 2013, Anhui University of Science \& Technology, Huainan, Anhui Province, P.R. China 


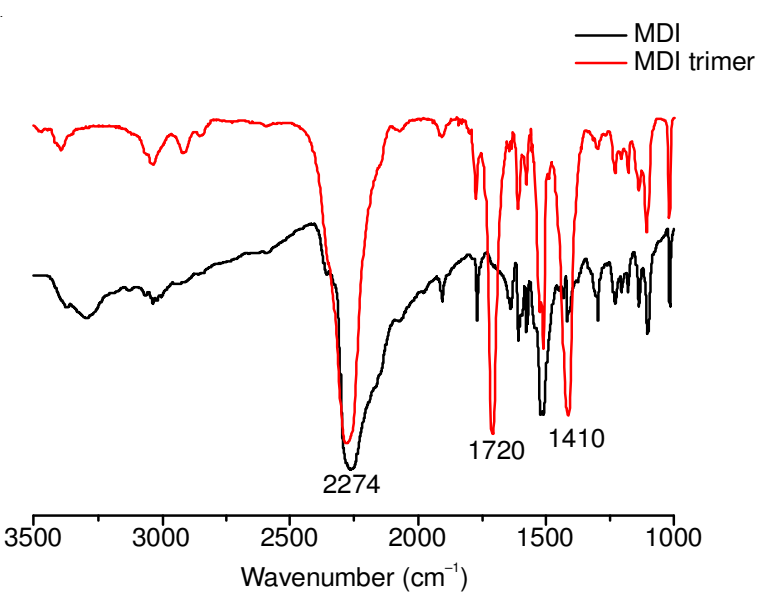

Fig. 1. Infrared spectroscopy of MDI and MDI- trimer

so the carbodiimide structure is not existed in the product. So the product is proved to be MDI trimer.

Thermal stability: Fig. 2 shows the results of TG and DTG of MDI and MDI trimer. There is only one stage in the thermal degradation process of MDI monomer that between 150 and $300{ }^{\circ} \mathrm{C}$, which due to the volatilization of MDI. The weight loss of it is $91.11 \%$. While there is not obviously weight loss of MDI trimer before 300. There are two stages in the thermal degradation of MDI trimer. In the first stage that between 300 and $420^{\circ} \mathrm{C}$, the carbodiimide structure is formed because the remained-NCO group of MDI trimer continue to reaction and give off $\mathrm{CO}_{2}{ }^{10,11}$, as shown in Fig. 3, the weight loss of the first stage is $10.03 \%$. The second stage that between 420 and $620{ }^{\circ} \mathrm{C}$, the polycarbodiimide is formed after decomposion of isocyanurate ring and give off $\mathrm{CO}_{2}$. The polycarbodiimide decomposed at $580^{\circ} \mathrm{C}$ and get a complex mixture of volatile products, leaving behind carbon residue.

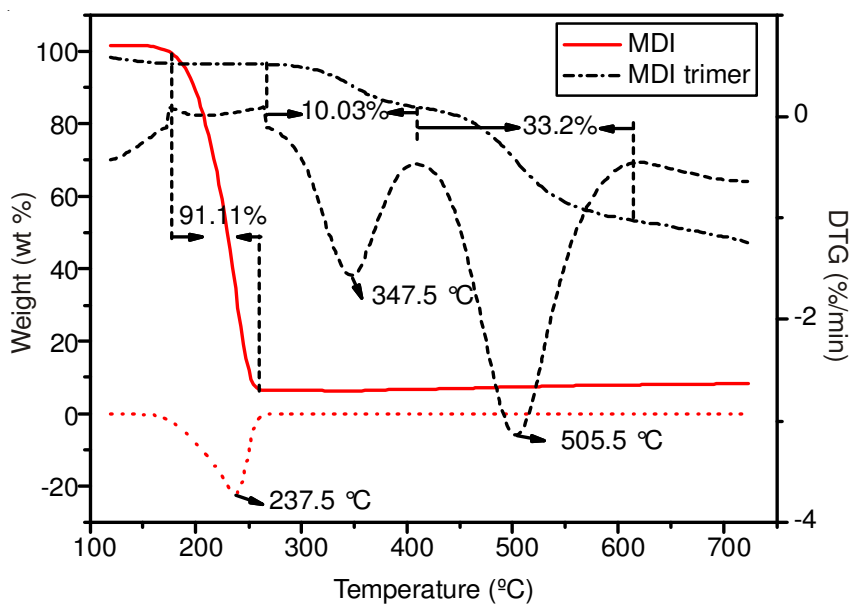

Fig. 2. TG and DTG of MDI and MDI- trimer

The decomposition product of MDI trimer under different temperatures are tracked by infrared as shown in Fig. 4. The absorption peak of cabodiimide structure is found at $2160 \mathrm{~cm}^{-1}$ in MDI trimer after $400^{\circ} \mathrm{C}$ carbonization, $\mathrm{C}-\mathrm{N}$ stretching vibration peak is found at $1520 \mathrm{~cm}^{-1}$ and $\mathrm{C}=\mathrm{O}$ stretching vibration peak is found at $1600 \mathrm{~cm}^{-1}$. There are not big difference between infrared spectroscopy of MDI trimer after $500^{\circ} \mathrm{C}$ carbonization and after $800^{\circ} \mathrm{C}$ carbonization. The Ar- $\mathrm{H}$ stretching vibration

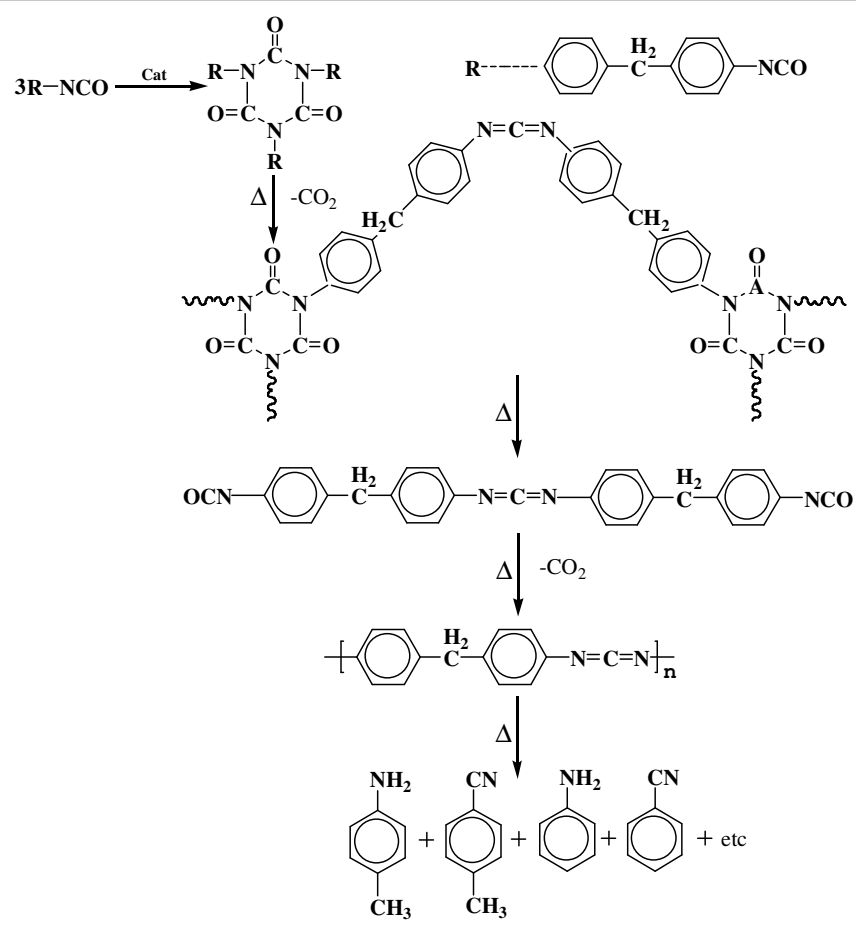

Fig. 3. Thermal degradation process of MDI-trimer

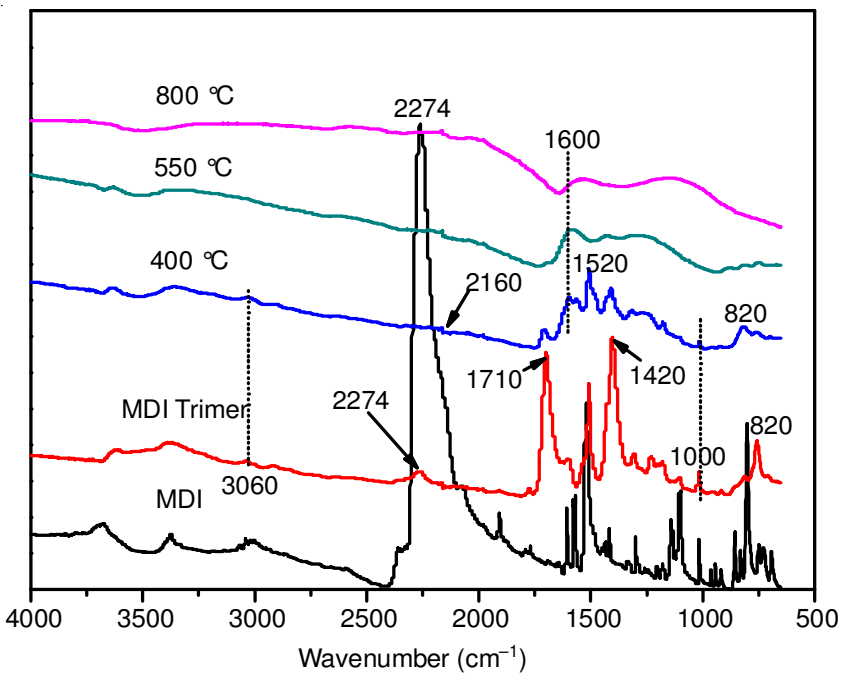

Fig. 4. Infrared spectroscopy of MDI-trimer before and after carbonization

peak is disappeared at $3060 \mathrm{~cm}^{-1}$ and the disappearance of absorption peak at $820 \mathrm{~cm}^{-1}$ is the result of para double instead $\mathrm{Ar}-\mathrm{C}$ and $\mathrm{Ar}-\mathrm{N}$ bond fission, remaining carbon residue at last.

X-Ray diffraction analysis: The MDI trimer and the product after carbonizationare both present typical amorphous structures are shown in Fig. 5. The relatively narrow peak that has symmetrical peak shape is found at $18^{\circ}$ diffraction angle in MDI trimer, which reflects the molecular space configuration is regular. The diffraction peak at $18^{\circ}$ in the product after $400^{\circ} \mathrm{C}$ carbonization is wider than it in MDI trimer, which mainly because the active-NCO groups of the MDI trimer react with each other and form a crosslinked structure. The diffraction peak gradually rises to a high angle with the carbonization temperature rises to $550^{\circ} \mathrm{C}$, the peak intensity become weaker and the peak type become wider, which shows that the molecular chain is broken and the arrangement of the chain segments are disorder after carbonization. 


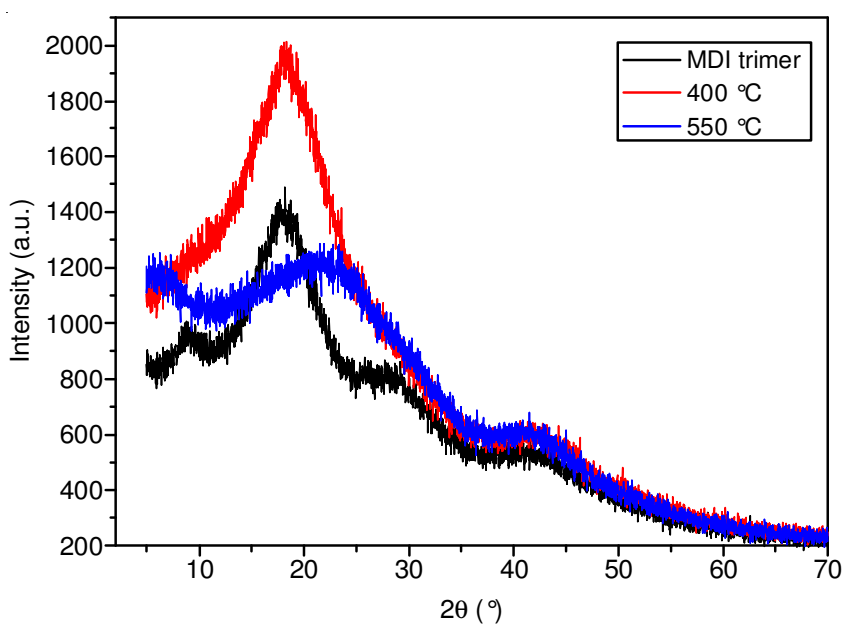

Fig. 5. XRD of MDI-trimer at different carbonization temperatures

Thermal degradation reaction kinetics: In this study, Ozawa method is used to calculate the activation energy. The activation energy (E) is calculated by using different DTG curve peak $\left(T_{p}\right)$ under different heating rate $\beta^{12}$.

$$
\log \beta=\log \left[\frac{\mathrm{AE}}{\mathrm{RG}(\alpha)}\right]-2.315-0.4567 \frac{\mathrm{E}}{\mathrm{RT}}
$$

The E can be calculated from the slope of the line that log $\beta$ as $Y$ axis and $1 / \mathrm{T}$ as $\mathrm{X}$ axis. The $\log \beta-1 / \mathrm{T}$ fitting curve is got according the Fig. 6 and Table-1.

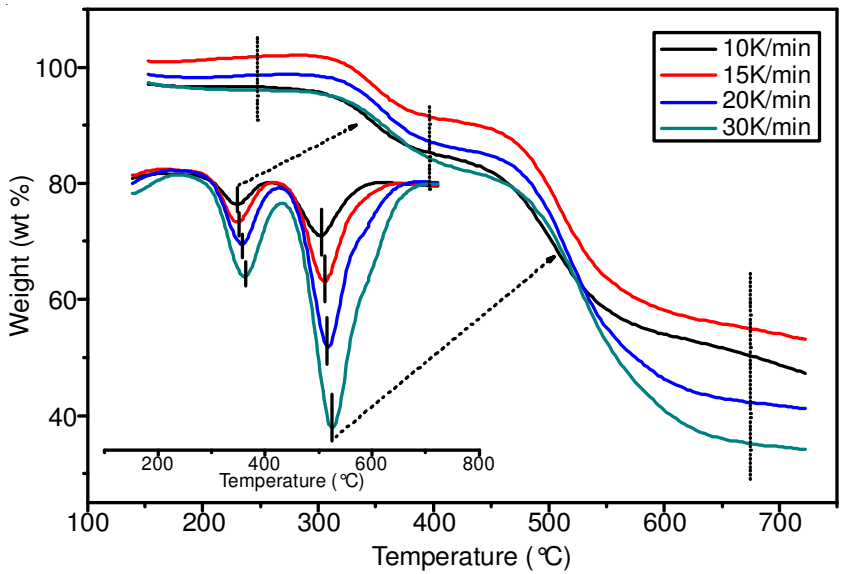

Fig. 6. TGA and DTG MDI-trimer at different heating rate

\begin{tabular}{cccc}
\multicolumn{4}{c}{ TABLE-1 } \\
\multicolumn{4}{c}{$\mathrm{T}_{\mathrm{p}}$ IN DTG OF MDI-TRIMER AT DIFFERENT HEATING RATE } \\
\hline Samples & Heating rate $\left(\mathrm{K} \mathrm{min}^{-1}\right)$ & $\mathrm{T}_{\mathrm{p} 1}\left({ }^{\circ} \mathrm{C}\right)$ & $\mathrm{T}_{\mathrm{p} 2}\left({ }^{\circ} \mathrm{C}\right)$ \\
\hline \multirow{4}{*}{ MDI-trimer } & 10 & 347 & 505 \\
& 15 & 347.5 & 510 \\
& 20 & 357 & 517 \\
& 30 & 360 & 525 \\
\hline
\end{tabular}

The two stages linear fitting curves are shown in Fig. 7. The first stage fitting curve equation expressed as $\mathrm{y}=18.88$ $11041.43 \mathrm{x}$, the line slope is -11041.43 , the correlation coefficient is 0.925 and the calculated activation energy is 200.99 $\mathrm{kJ} / \mathrm{mol}$. The second stage fitting curve equation expressed as $\mathrm{y}=19.37-14279.18 \mathrm{x}$, the line slope is -14279.18 , the correlation coefficient is 0.992 and the calculated activation energy is $259.94 \mathrm{~kJ} / \mathrm{mol}$. The result shows that the activation energy is relatively high in two stages.
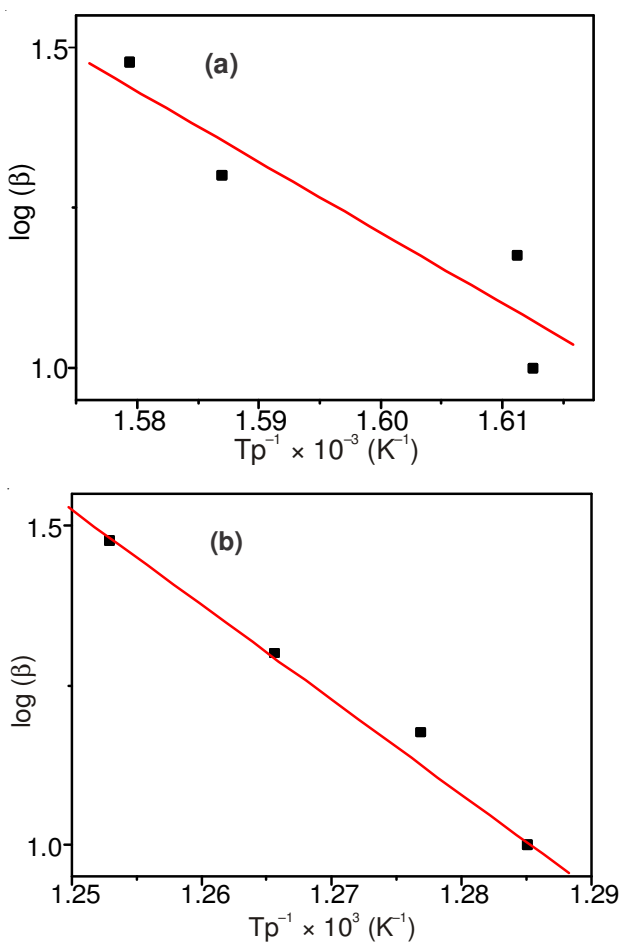

Fig. 7. Fitting curve of ozawa of MDI-trimer (a, the first stage; $b$, the second stage)

\section{Conclusion}

The product that synthesized by using solution polymerization is MDI trimer according to the result of Fourier infrared spectra. The thermal stability of MDI trimer is better than MDI. There are two stages through MDI trimer degradation process. The carbodiimide structure is formed in the first stage, the isocyanurate ring and carbodiimide structure resolved in the second stage. The activation energy of MDI trimer are calculated by Ozawa method.

\section{ACKNOWLEDGEMENTS}

This work was financially supported by the Natural Science Foundation of China (No. 21171004), the National Science \& Technology Pillar Program of China (No. 2011BAJ03B04, 2013BAJ01B05) and the Natural Science Foundation of Anhui Province Education Department (KJ2011A064).

\section{REFERENCES}

1. H.-J. Laas, R. Halpaap and C. Wamprecht, Polyether-Modified Polyisocyanate Mixtures having Improved Dispersibility in Water, US Patent 6426414 (2002)

2. W.-J. Li and Y.-L. Lin, Mater. Des., 2, 55 (2012).

3. C.-M. Song and D.-N. Wang, China Syn. Rubber Ind., 25, 12 (2002).

4. J.-H. Sheng, Techno-Economics in Petrochemical., 4, 40 (2005).

5. C. Jin, W.S. Li, G.Y. Lu and X.H. Yang, Chin. J. Appl. Chem., 22, 624 (2005).

6. W. Yin and J.L. Chu, Paint Coat. Ind., 29, 34 (1999).

7. X.P. Gao, Y.Q. Zhang, G.Y. Cao and J.X. Li, Chem. Propell. Polym. Mater., 3, 10 (2005).

8. W.H. Xia, G.B. Wang, C.Y. Ha and M.M. Shen, Guangzhou Chem., 27, 1 (2002).

9. A.L. Daniel da Silva, J.M. Martín-Martínez and J.C.M. Bordado, Int. J. Adhes. Adhes., 26, 355 (2006).

10. D. Sheehan, A.P. Bentz and J.C. Petropoulos, J. Appl. Polym. Sci., 19, 47 (1962).

11. J. Jiricny and C.B. Reese, Br. Polym. J., 12, 81 (1980).

12. C. Popescu, Thermochim. Acta, 285, 309 (1996). 